\title{
The prognostic role of the cancer stem cell marker CD44 in ovarian cancer: a meta-analysis
}

Jiaying Lin ${ }^{1}$ and Ding Ding ${ }^{2^{*}}$

\begin{abstract}
Background: CD44 has recently been reported as a cancer stem cell marker in ovarian cancer. However, the clinicopathological and prognostic value of this marker in ovarian cancer remains controversial; Here, we aimed to investigate the correlation between CD44 expression and the clinicopathological features or survival of ovarian cancer patients.

Methods: An extensive literature search in the PubMed, EMBASE, and Wanfang databases (up to June 1, 2016) was conducted to identify studies that assessed the clinical or prognostic significance of CD44 expression in ovarian cancer. A meta-analysis was then performed to clarify the association between CD44 expression and clinical outcomes of ovarian cancer patients.

Results: A total of 18 publications consisting of 2161 patients were included for this meta-analysis. Our data reveal that CD44-positive expression in ovarian cancers were significantly associated with a high TMN stage (pooled $\mathrm{OR}=2.11,95 \% \mathrm{Cl} 1.26-3.53, \mathrm{P}=0.004)$ and poor 5-year overall survival $(\mathrm{RR}=1.42,95 \% \mathrm{Cl} 1.01-2.00, \mathrm{P}=0.05)$. However, CD44 expression was not associated with tumor grade, lymphatic metastasis, age of the patients, residual tumor size, response to chemotherapy, or ascites volume $(P>0.05)$.
\end{abstract}

Conclusion: Detection of CD44 may be an effective tool for pathological diagnosis and prognostic prediction of ovarian cancer patients in clinical applications.

Keywords: Ovarian cancer, Cancer stem cells, CD44, Prognosis

\section{Background}

Ovarian cancer is the leading cause of death from gynecologic malignancy [1]. Although most ovarian cancer patients initially respond very well to platinumbased chemotherapy, the vast majority of patients will ultimately develop cancer recurrence and succumb to chemo-resistant disease [1].

CSCs represent a subpopulation of cancer cells that possess tumor initiation and self-renewal capacity and have been implicated in driving tumor growth, metastasis, and relapse following therapy in a wide variety of human cancers such as breast and ovarian cancers [2,3].

\footnotetext{
*Correspondence: dingdingGYN1208@163.com

2 Department of Gynecology, Obstetrics and Gynecology Hospital, Fudan University, 419 Fangxie Road, Shanghai 200011, China

Full list of author information is available at the end of the article
}

In recent years, CSCs have also been found to contribute to the poor clinical outcome of ovarian cancer patients [4]. Furthermore, it has been suggested that CSC markers, such as CD44, ALDH1 and CD133, may serve as valuable prognostic indicators for ovarian cancer $[4,5]$. Among these CSC markers, CD44 is the most frequently reported in ovarian cancer. Several studies have demonstrated that CD44 can be used to isolate cancer cells with stem cell-like and cancer-initiating properties from other populations of cancer cells [6-8].

CD44, which consists of four functional domains, plays important roles in cell-matrix adhesion, signal transduction, cytoskeletal rearrangement, and cell migration [9]. Intriguingly, the proximal extracellular domain is the site for alternative splicing of the CD44 mRNA that results in various isoforms of CD44. The CD44 standard form 
(CD44s) and CD44 variants (CD44v) participate in cellcell and cell-matrix interactions, cell migration, lymphocytehoming, and tumorigenesis. CD44v6 has particularly gained a lot of attention in recent years, since the expression of this variant has been found to be upregulated in a variety of epithelial malignancies, such as head and neck, colon, endometrium and ovarian cancers. CD44v6 may be implicated in the activation of PI3K/Akt and MAPK pathways, which can then inhibit apoptosis and promote invasion and metastasis of cancer cells [10-14].

Although the association between the expression of CD44 or its isoforms and the survival of patients with ovarian cancer has been well investigated, the prognostic values of CD44, CD44s, and CD44v6 in predicting the survival of patients with ovarian cancer remains controversial [15-19]. In the present study, we performed a systematic review and meta-analysis of the published literature to examine the association of the expression of CD44 or its isoforms with the clinicopathological features and the prognosis of ovarian cancer patients. These findings may help to uncover valuable marker that may enable the prognostic stratification of ovarian cancer patients and guide the management of these patients in the future.

\section{Methods}

\section{Search strategy}

The electronic databases, including Pubmed, Embase, and Wanfang, were searched for studies that investigated the correlation of the CD44 expression and clinicopathological parameters and prognosis in ovarian cancer patients. The literature search was updated until June 1, 2016. The search terms were used as follows: "CD44", "ovarian neoplasms" or "ovary neoplasms" or "ovarian cancer" or "cancer of ovary". Review articles and the citations from all the retrieved reports were further manually reviewed to identify other relevant publications. The titles and abstracts of identified reports were examined to exclude any irrelevant publications. The full-text of the remaining articles were further inspected to determine whether they reported the correlation of the expression of CD44 or its isoforms and the clinicopathological features and prognosis of ovarian cancer patients.

\section{Inclusion and exclusion criteria}

The studies included for this meta-analysis met the following criteria: (1) Definitive diagnosis of ovarian cancer was made on the basis of histopathological findings; (2) Studies that examined the protein expression of CD44, CD44s, or CD44v6 in ovarian tissues instead of that in the serum or any other types of specimen; (3) studies that investigated the correlation of the expression of CD44, $\mathrm{CD} 44 \mathrm{~s}$, or CD44v6 with clinicopathological features;
(4) studies that reported the association of the expression of CD44 or its isoforms with overall survival (OS) of ovarian cancer patients. There was no limitation on the minimum number of patients in each study. When there were multiple articles by the same group based on similar patient populations, only the largest or the most recent article was included. The exclusion criteria for this metaanalysis include: (a) Studies were not associated with the topic of interest; (b) researchers did not make the definitive diagnosis based on histopathologic findings or they did not carried out clinical and imaging follow-up for at least 6 months; (c) studies associated with other diseases (d); non-original articles; (e) data could not be extracted; and (f) duplicate data from the same or similar patient population.

\section{Data extraction}

The following information was extracted from the retrieved full-text papers: lead author, country of the patients, ethnicity, publication year, time of sample collection, the pathological stages of tumors, number of patients, types of research techniques, the ages of the patients, and the choice of cut-off scores for the definition of positive staining or staining intensity. The included studies can be divided into two major groups based on the research objectives of these studies. One group evaluated the correlation between the expression of CD44, CD44s, or CD44v6 and the clinicopathological parameters, including TMN stage, tumor grade, lymphatic metastasis, age of the patients, residual tumor size, responses to chemotherapy, and ascites volume. The other group investigated the association between the expression of CD44, CD44s, or CD44v6 and the OS or disease-free survival (DFS).

\section{Statistical analysis}

The meta-analysis was performed as previously described [20]. Odds ratios (ORs) with 95\% confidence interval (CI) were employed to evaluate the association between the expression of CD44, CD44s, or CD44v6 and the clinicopathological features for the patients with ovarian cancer, including TMN stage, tumor grade, lymphatic metastasis, age of the patients, residual tumor size, responses to chemotherapy, and ascites volume. By contrast, the risk ratio (RR) was used for assessing the correlation of the expression of CD44, CD44s, or CD44v6 and the OS or DFS. If RRs were not reported directly in the published articles, the data from those papers were then used to calculate the RR according to the methods described by Parmar et al. [21]. Heterogeneity across studies was evaluated with the $\mathrm{Q}$ test and $\mathrm{P}$ values. ORs and RRs were calculated using a random-effects model when the $\mathrm{P}$ value was less than 0.05 . Otherwise, a fixed-effects model 
was applied. The Begg's funnel plot and Egger's test were used to assess publication bias. All statistical analyses were carried out using Review manager software (Revman version 5.3.5.). The difference will be considered statistically significant when two-sided $P$ values are less than 0.05 .

\section{Results}

\section{Characteristics of the included studies}

A total of 451 articles were originally identified for the meta-analysis after searching the electronic databases PubMed, Embase, and Wanfang. 421 reports were excluded after closely reviewing the titles and abstracts. Eventually, the extensive review of the full-text articles yielded a total of 18 studies consisting of 2161 patients that met the inclusion criteria for this meta-analysis [1519, 22-34] (Fig. 1). The main characteristics of the eligible studies are summarized in Table 1. Among the included studies, 17 articles assessed the correlation between the expression of CD44 or its isoforms and the clinicopathological features of ovarian cancer, whereas the association of CD44 expression with OS or DFS was examined using the Kaplan-Meier method in 12 of these studies.

\section{The correlation of CD44v6 expression}

\section{with clinicopathological parameters}

Notably, our analysis based on the random-effect model reveals that the expression of CD44v6 in ovarian cancers is significantly associated with a high TMN stage (pooled OR $=2.11,95 \%$ CI 1.26-3.53, $\mathrm{P}=0.004$ ) (Fig. 2).

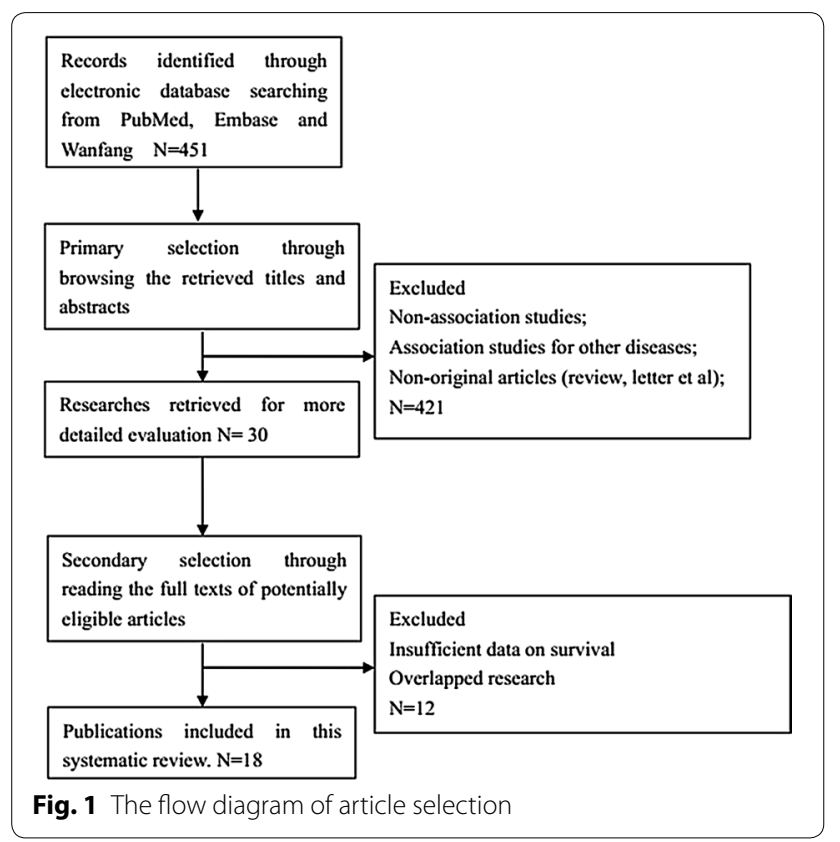

However, there is no significant correlation between CD44 expression and tumor grade (pooled OR $=2.08$, 95\% CI 0.91-4.74, $\mathrm{P}=0.08$, random-effect model) (Fig. 3), lymphatic metastasis (pooled OR $=1.76,95 \%$ CI $0.78-3.95, \mathrm{P}=0.17$, random-effect model) (Fig. 4), age of the patients (pooled OR $=1.60,95 \%$ CI 0.58-1.93, $\mathrm{P}=0.84$, fixed-effect model) (Fig. 5), residual tumor size (pooled OR $=1.01,95 \%$ CI $0.30-3.40, \mathrm{P}=0.99$, randomeffect model) (Fig. 6), response to chemotherapy (pooled $\mathrm{OR}=2.71,95 \%$ CI $0.90-8.22, \mathrm{P}=0.08$, random-effect model) (Fig. 7), or ascites volume (pooled OR $=1.61,95 \%$ CI 0.66-3.94, $\mathrm{P}=$ 0.29, random-effect model) (Fig. 8).

\section{The correlation between CD44 expression and the prognosis of ovarian cancer}

Next, we analyzed the impact of CD44 expression on the survival of ovarian cancer patients. As shown in Fig. 3, our meta-analysis of the pooled data from the ten studies showed that CD44 expression is significantly associated with a poor 5 -year $\mathrm{OS}(\mathrm{RR}=1.42,95 \% \mathrm{CI} 1.01-2.00$, $\mathrm{P}=0.05$ ) (Fig. 9). Nevertheless, CD44 expression is not significantly correlated with DFS $(\mathrm{RR}=1.23,95 \% \mathrm{CI}$ 0.86-1.77, P < 0.25) (Fig. 10).

\section{Sensitivity analysis}

In order to rule out a bias introduced by the low numbers of eligible publications for our meta-analysis, we then performed a sensitivity analysis. For this purpose, an individual study included in the meta-analysis was removed for each round of analysis to investigate the influence of the single dataset of the particular study on the pooled ORs. Our data suggest that the corresponding pooled ORs were not significantly altered by the removal of any study (data not shown), indicating that our results are statistically robust.

\section{Publication bias}

Next we evaluated the publication bias regarding our meta-analysis using Begg's funnel plot and Egger's test. The Begg's funnel plots of the meta-analyses of the correlation between CD44 expression and the clinicopathological parameters and 5-year OS or DFS did not show an evident asymmetrical shape. Consistently, the results of Egger's test also rule out publication bias involving our meta-analysis (Table 2).

\section{Discussion}

It has been hypothesized that the formation and progression of cancers are driven by CSCs which represent a minor population in cancer cells [35]. More importantly, CSCs are considered to be responsible for chemotherapy resistance, metastasis, and postoperative recurrence [36]. A significant fraction of ovarian cancer patients 


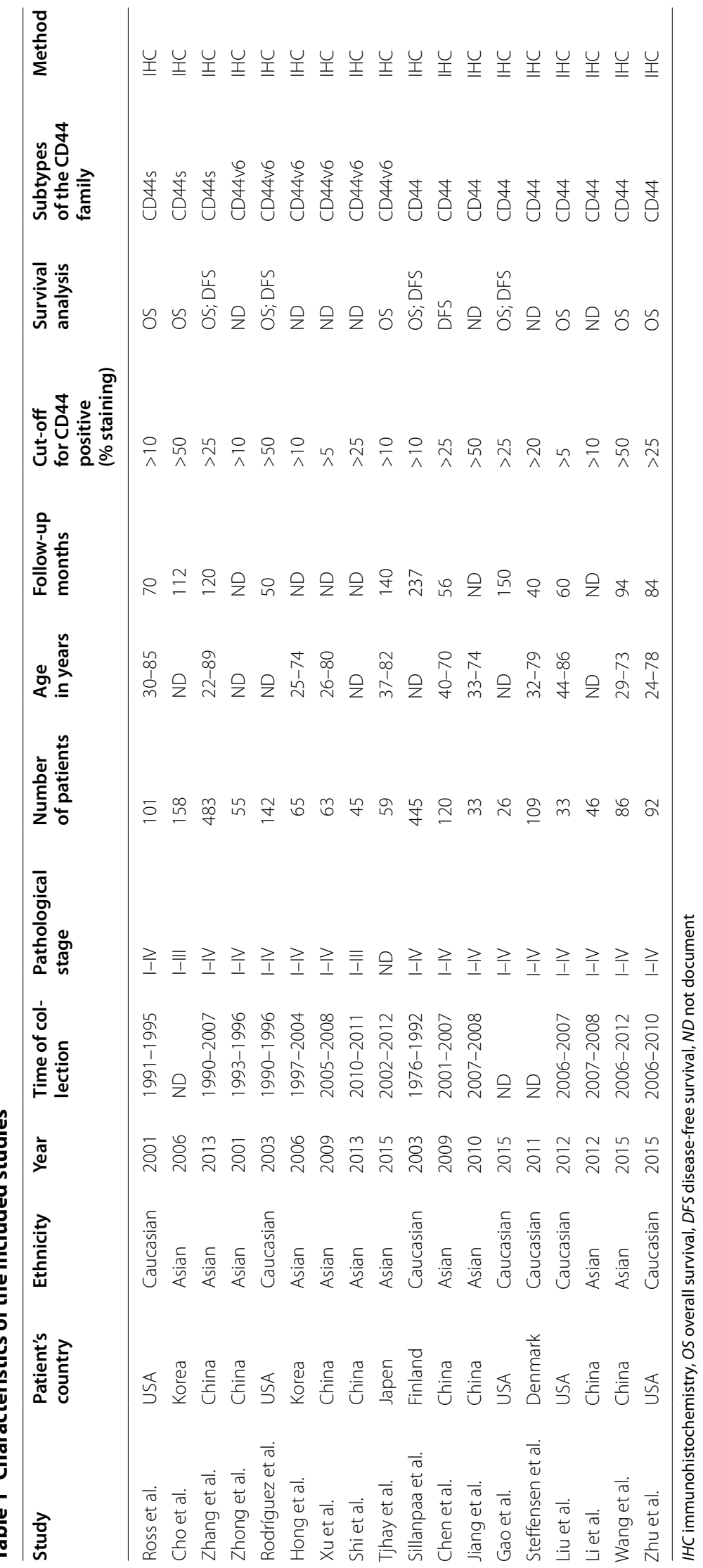




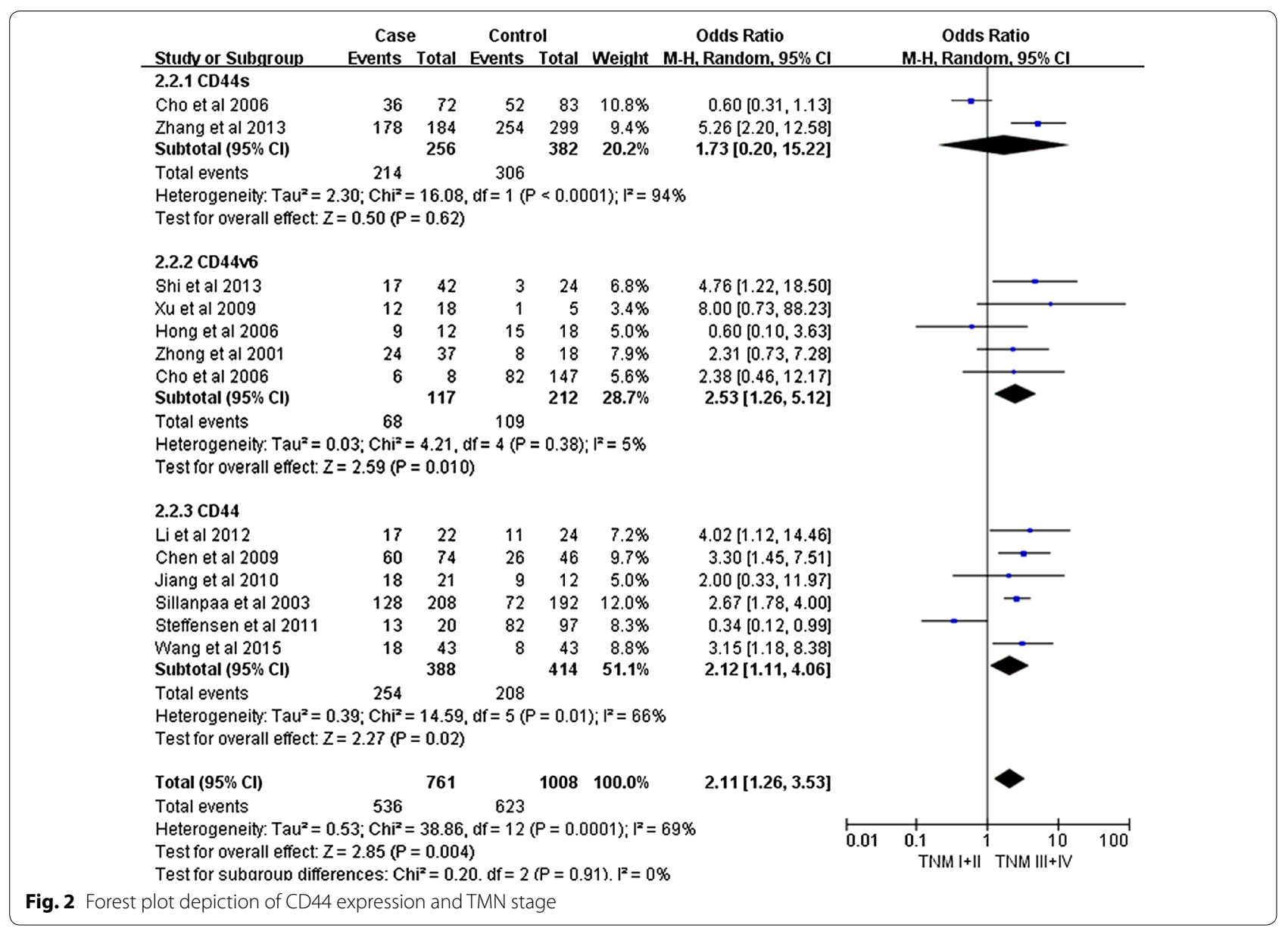

will ultimately develop cancer recurrence and succumb to chemo-resistant disease [37]. Furthermore, to date, there are still no reliable markers available for the diagnosis and prognosis of ovarian cancer patients. Therefore, it remains urgent to search for a reliable prognostic parameter applicable in clinical practice to predict disease outcomes in ovarian cancer. CD44 is an important cell surface marker for isolating CSCs from tumors and is correlate with poor prognosis in various human cancers [7, 38-40]. Intriguingly, in this study, we found that the expression of CD44v6 in ovarian cancers is significantly associated with a high TMN stage. Moreover, our findings revealed that CD44 expression is inversely correlated with a poor 5-year OS. However,we find no significant association between CD44 positivity and tumor grade, lymphatic metastasis, age of the patients, residual tumor size, response to chemotherapy, or ascites volume. These data indicate that CD44 expression may be used in the pathological evaluation of tissue histology to predict ovarian cancer prognosis in the future.

CD44 was identified as a surface glycoprotein and a lymphocyte homing receptor found on lymphoid and epithelial cells in 1982 [41]. Its main function on lymphocytes is mediating interaction with the endothelium [42]. Substantial evidence indicates that CD44 has been implicated in cancer invasion and metastasis. CD44v6, one of the major variants of CD44, could modulate the conjugation of CD44s and hyaluronic acid (HA), or enhance the metastasis of tumor by conjugating with HA [43]. CD44 plays an essential role in epithelial mesenchymal transition (EMT), one of the most important events in the cancer invasion process $[44,45]$. Consistently, in some epithelial cells, the EMT process was accompanied by CD44 isoform switch from CD44v6 to CD44s, and CD44s has been proved to promote the EMT process [46]. Moreover, CD44 also plays a critical role in cell migration. After activated by its binding to hyaluronan, the cytoplasmic tail of CD44 in turn bind to the actin cytoskeleton and it would be translocated to the leading edge of the migrating cells. Thereafter, CD44 binds to CD62 on the endothelial cells, enabling the migrating cells to roll on the endothelia cells, which is the initial step of cell migration named extravasation [47]. Because of the important role that CD44 plays in cancer invasion 


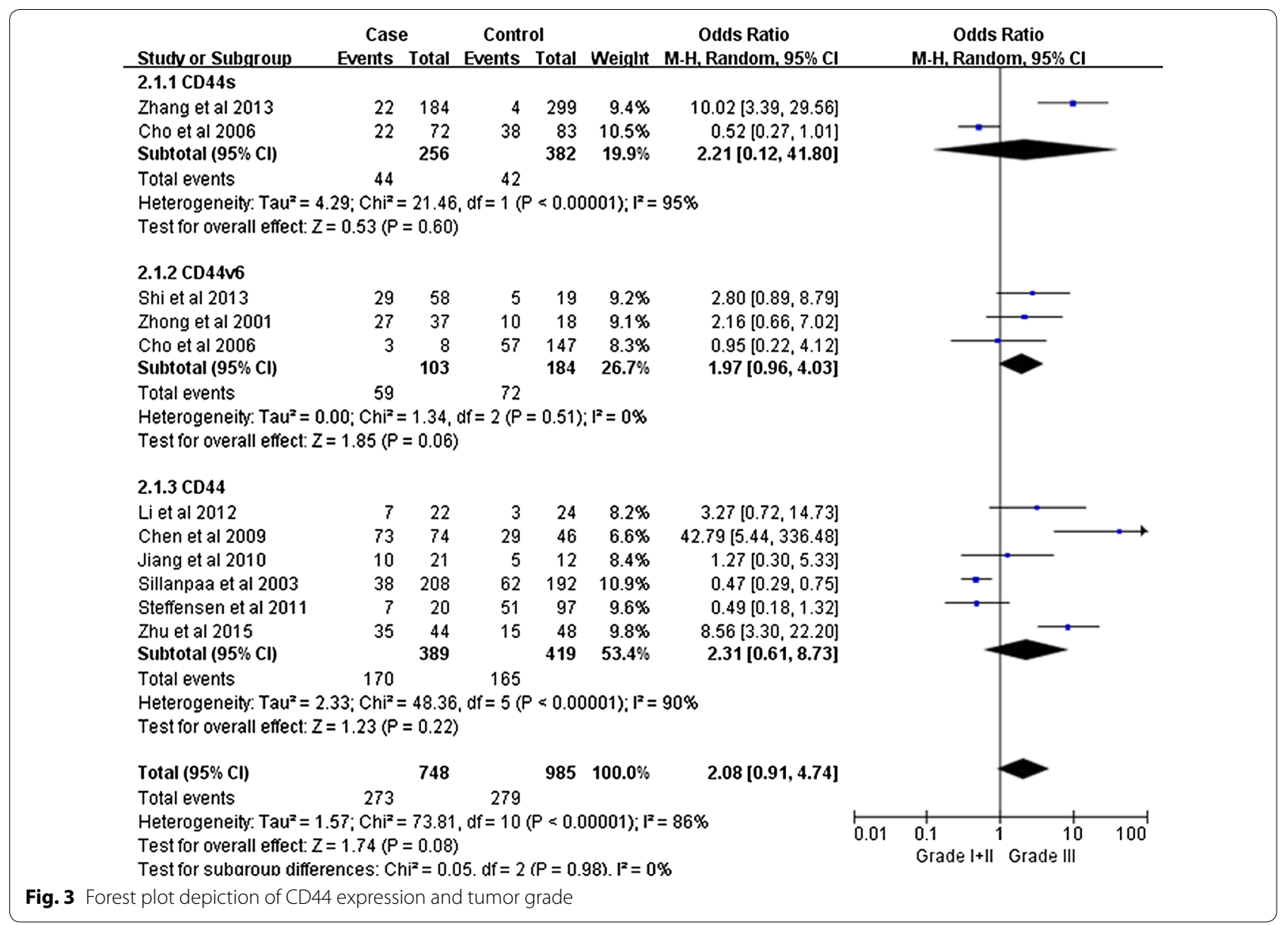

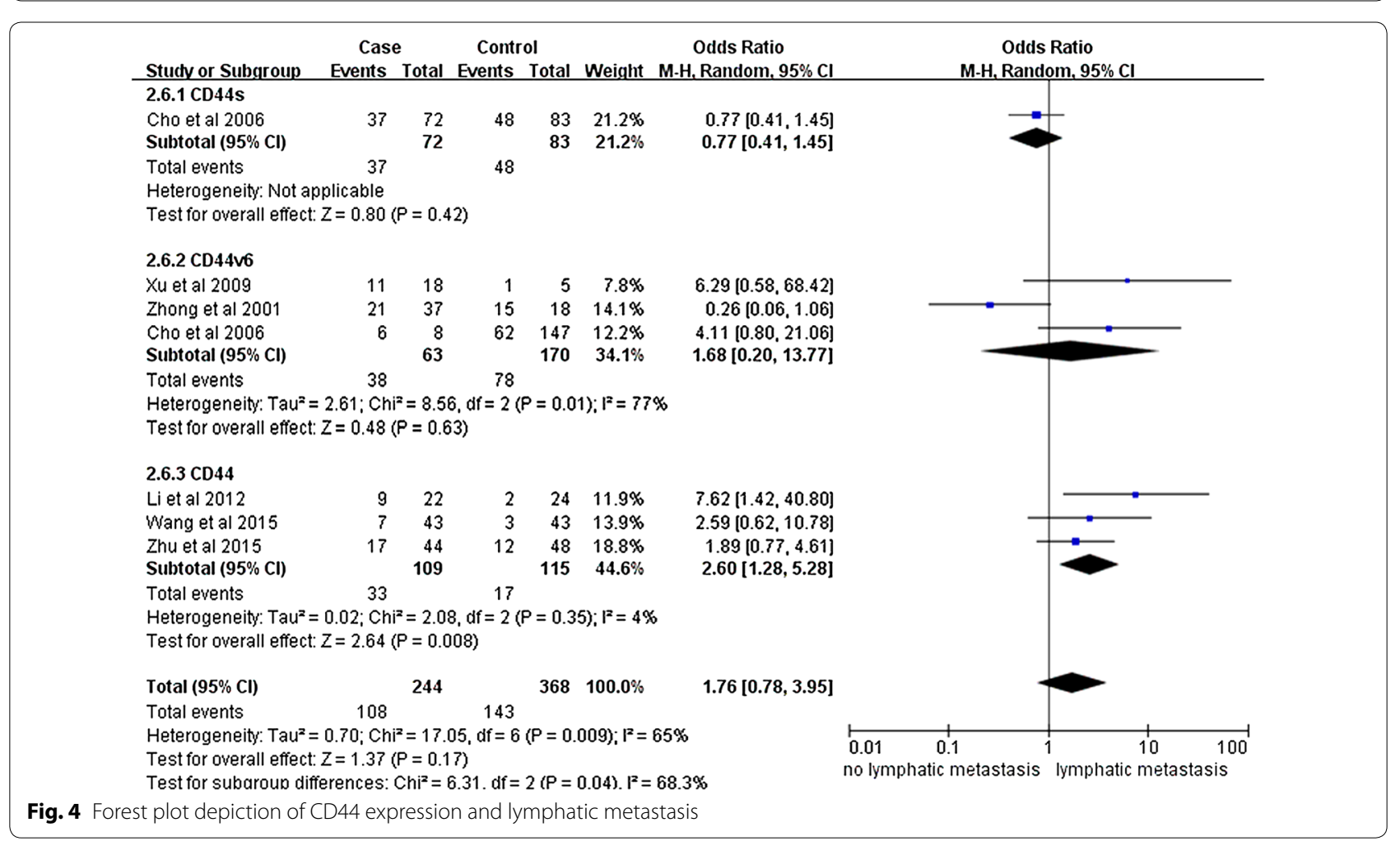




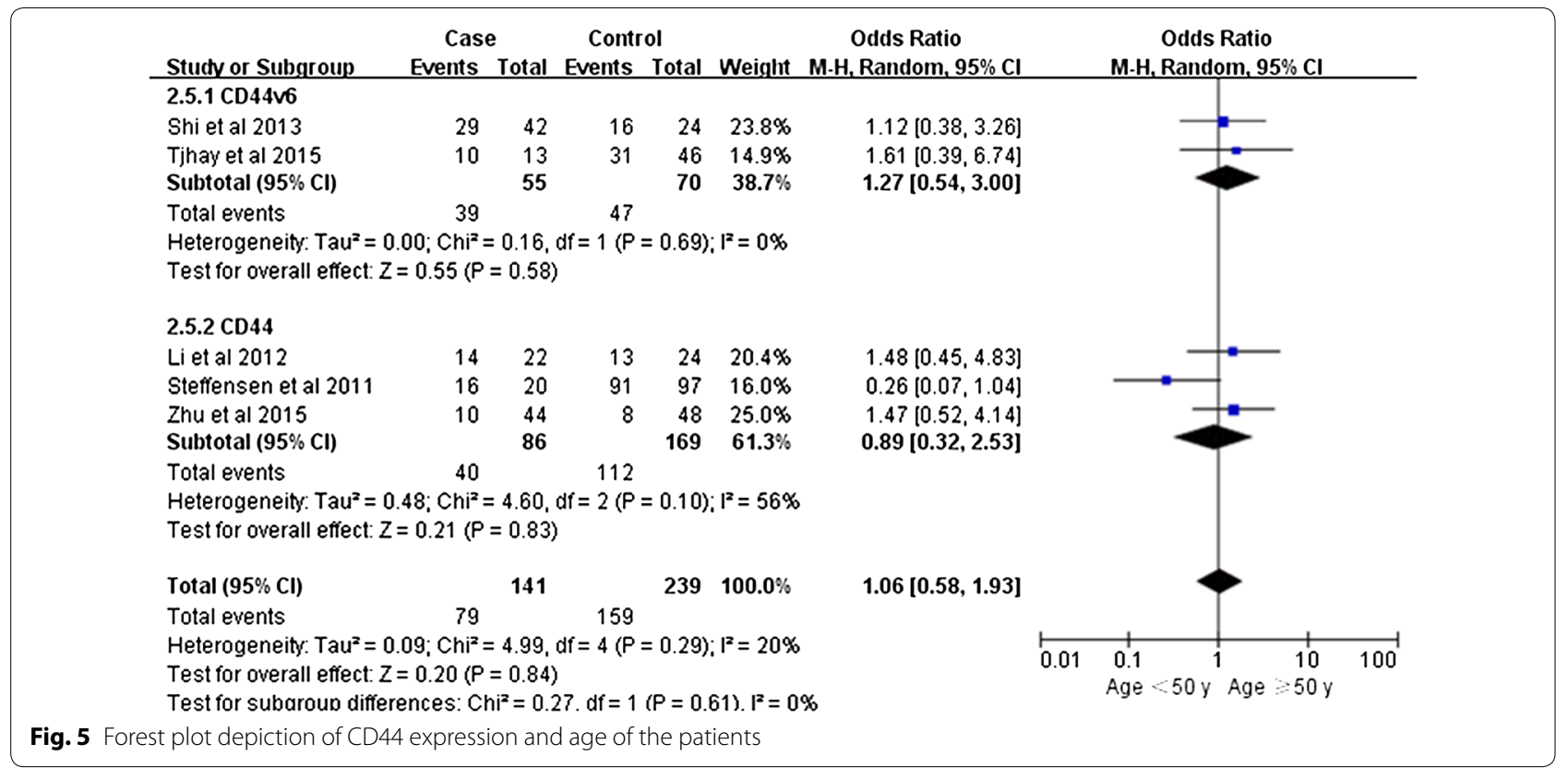

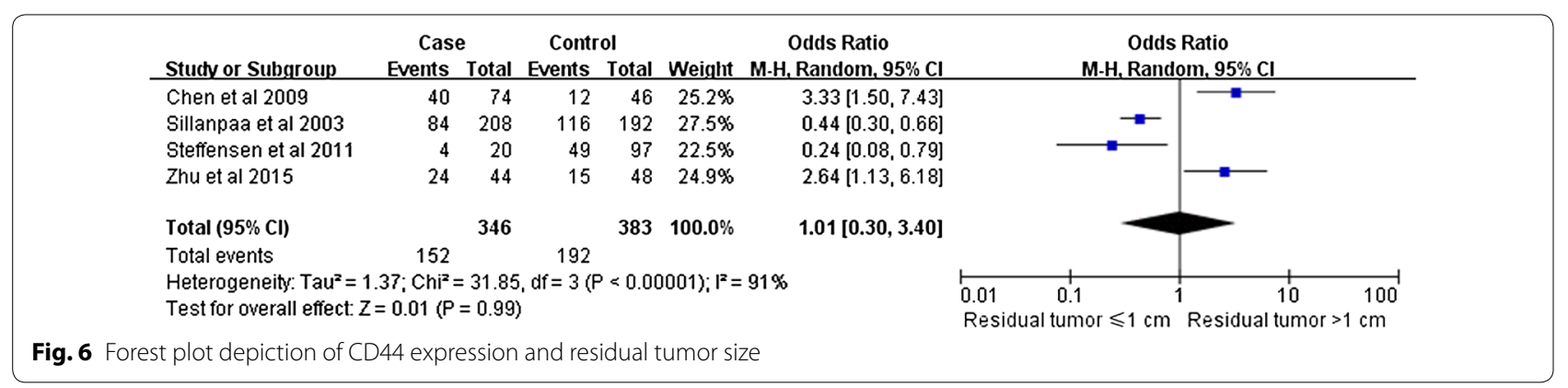

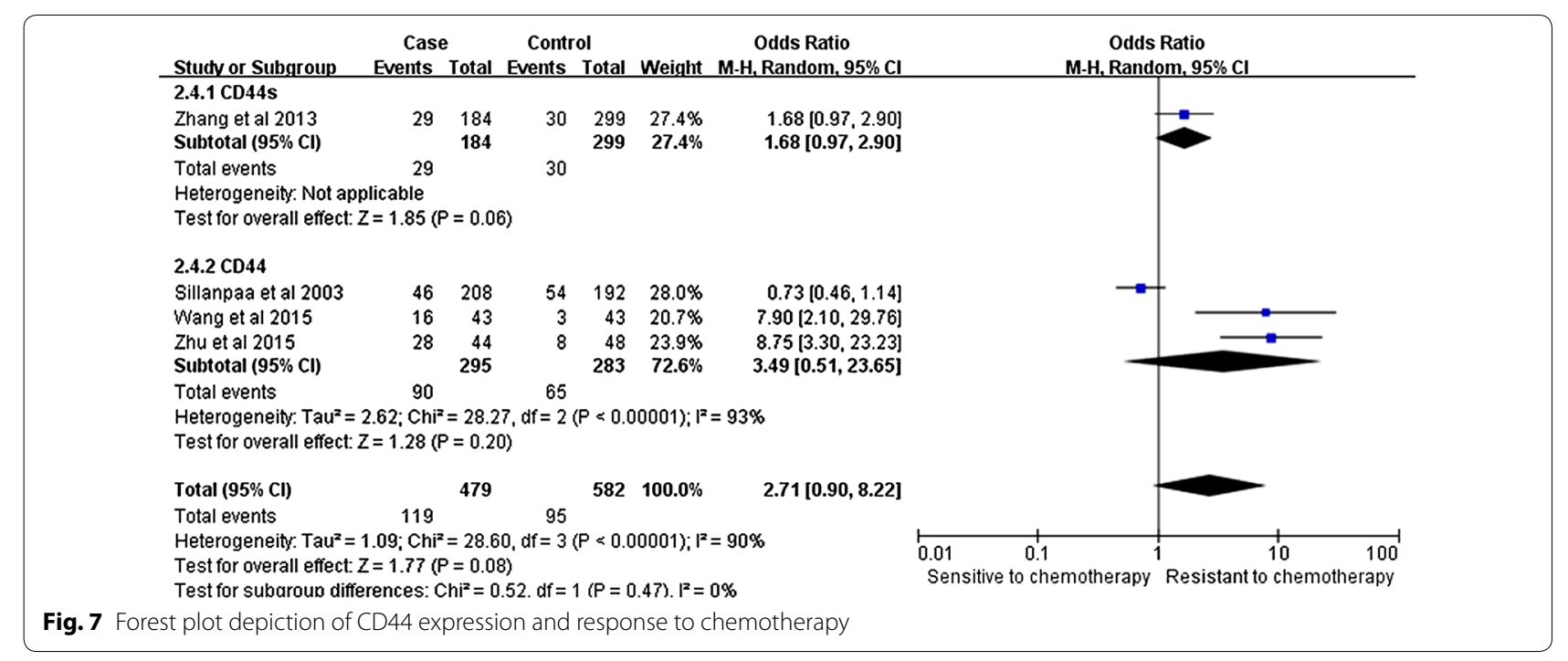




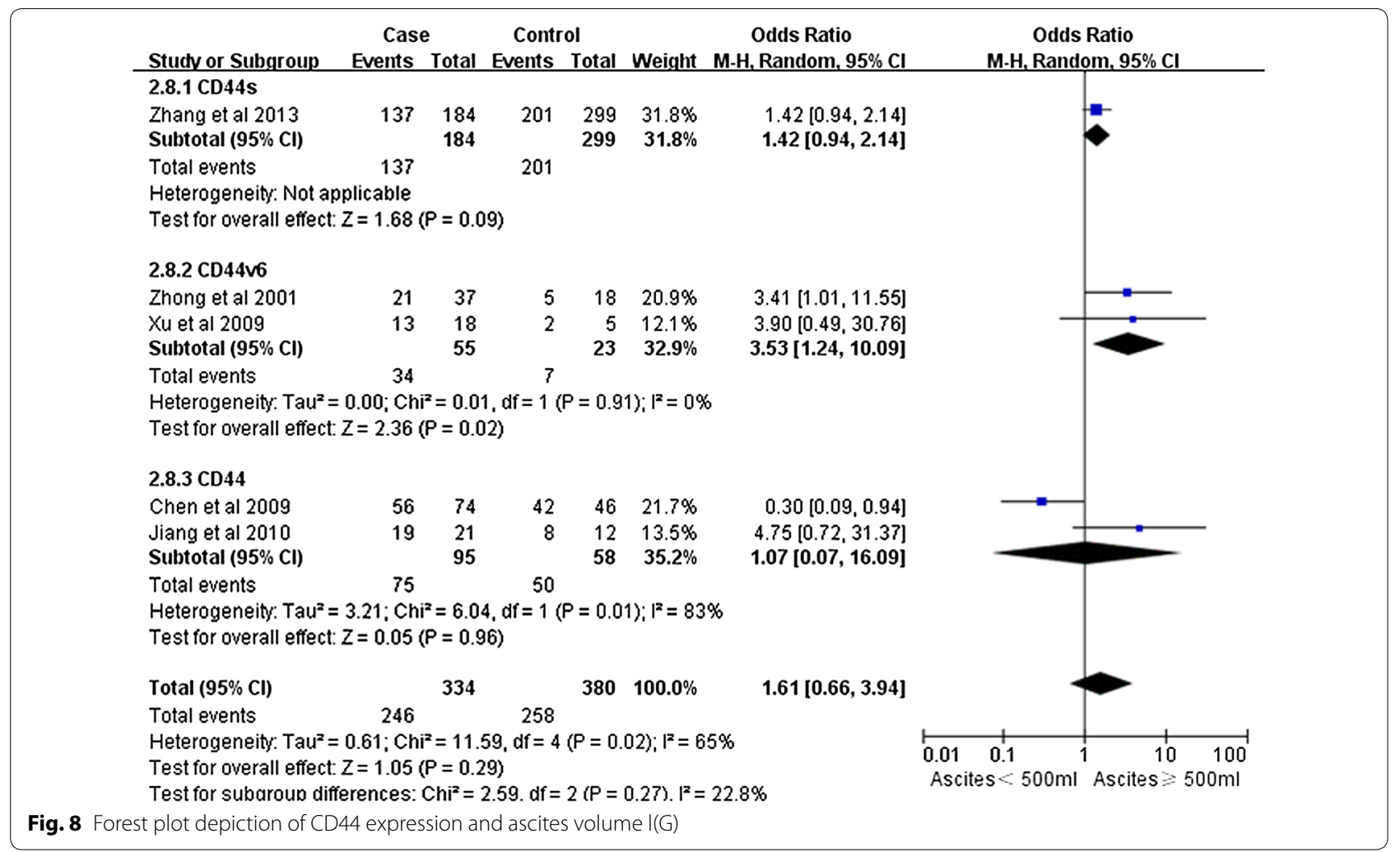

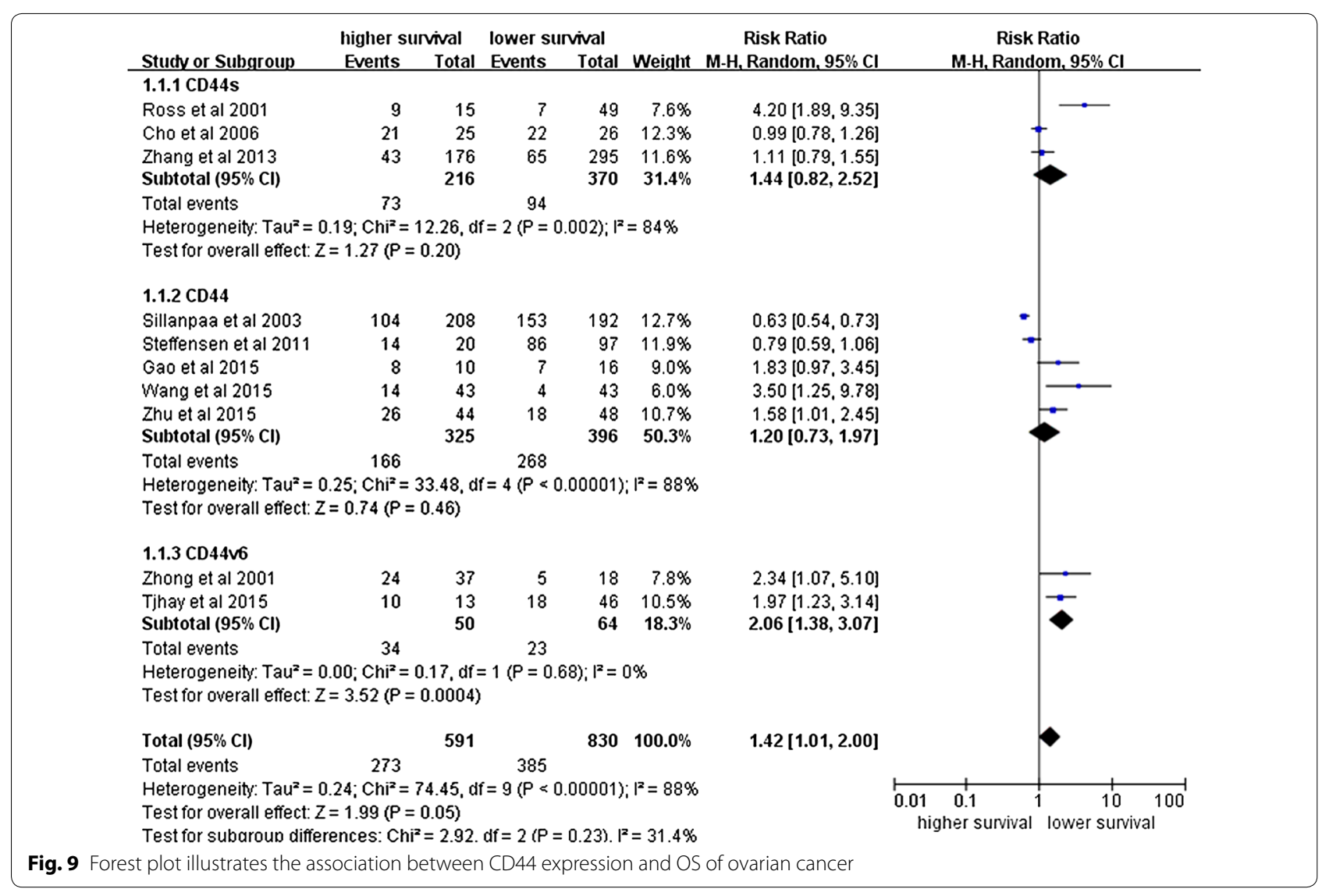




\begin{tabular}{|c|c|c|c|c|c|c|c|c|}
\hline \multirow{2}{*}{\multicolumn{2}{|c|}{ Stucty or Subgroup }} & \multicolumn{2}{|c|}{ higher survival } & \multicolumn{2}{|c|}{ lower survival } & Weight $\mathrm{N}$ & $\begin{array}{c}\text { Risk Ratio } \\
\text { M-H, Random, } 95 \% \mathrm{Cl}\end{array}$ & $\begin{array}{c}\text { Risk Ratio } \\
\text { M-H, Random. } 95 \% \mathrm{Cl}\end{array}$ \\
\hline & & & & & & & & \\
\hline & Sillanpaa et al 2003 & 135 & 208 & 105 & 192 & $21.8 \%$ & $1.19[1.01,1.40]$ & $=$ \\
\hline & Chen et al 2009 & 47 & 74 & 40 & 46 & $21.2 \%$ & $0.73[0.59,0.90]$ & $=$ \\
\hline & Gao et al 2015 & 9 & 10 & 14 & 16 & $20.1 \%$ & $1.03[0.78,1.36]$ & + \\
\hline & Subtotal $(95 \% \mathrm{Cl})$ & & 292 & & 254 & $63.0 \%$ & $0.96[0.70,1.33]$ & \\
\hline & Total events & 191 & & 159 & & & & \\
\hline & $\begin{array}{l}\text { Heterogeneity: } \operatorname{Tau}^{2}= \\
\text { Test for overall effect: } 2\end{array}$ & $\begin{array}{l}1.07 ; \mathrm{Chi}^{2}= \\
=0.22(\mathrm{P}=\end{array}$ & $\begin{array}{l}\text { 13.96, df } \\
0.82)\end{array}$ & $f=2(P=$ & $.0009) ;$ & $I^{2}=86 \%$ & & \\
\hline & 1.2.2 CD44s & & & & & & & \\
\hline & Zhang et al 2013 & 35 & 94 & 46 & 172 & $18.5 \%$ & $1.39[0.97,2.00]$ & $=$ \\
\hline & Subtotal $(95 \% \mathrm{Cl})$ & & 94 & & 172 & $18.5 \%$ & $1.39[0.97,2.00]$ & ( \\
\hline & Total events & 35 & & 46 & & & & \\
\hline & Heterogeneity: Not app & licable & & & & & & \\
\hline & Test for overall effect: 2 & $=1.80\langle\mathrm{P}=$ & $0.07)$ & & & & & \\
\hline & 1.2.3 CD44v6 & & & & & & & \\
\hline & Rodríguez et al 2003 & 28 & 36 & 26 & 85 & $18.5 \%$ & $2.54[1.77,3.66]$ & - \\
\hline & Subtotal $(95 \% \mathrm{Cl})$ & & 36 & & 85 & $18.5 \%$ & $2.54[1.77,3.66]$ & \\
\hline & Total events & 28 & & 26 & & & & \\
\hline & Heterogeneity: Not app & licable & & & & & & \\
\hline & Test for overall effect: $z$ & $=5.01 \mathrm{P}$ & 0.00001 & & & & & \\
\hline & Total $(95 \% \mathrm{Cl})$ & & 422 & & 511 & $100.0 \%$ & $1.23[0.86,1.77]$ & 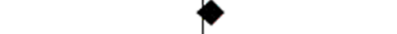 \\
\hline & Total events & 254 & & 231 & & & & \\
\hline & Heterogeneity: $\operatorname{Tau}^{2}=$ & $15 ; \mathrm{Chi}^{2}=$ & 40.62 , df & $f=4(P<$ & $.00001)$ & $y_{12}=90 \%$ & & $\begin{array}{lllll}0.01 & 0.1 & 1 & 10 & 100\end{array}$ \\
\hline & Test for overall effect: $z$ & $=1.14(\mathrm{P}=$ & $0.25)$ & de- 20 & $=0.000$ & $I^{2}=8709$ & & higher survival lower survival \\
\hline g. 10 & $\begin{array}{l}\text { Test for subaroun diffe } \\
\text { est plot illustrates the }\end{array}$ & $\begin{array}{l}\text { ences: } \mathrm{Ch} \\
\text { ssociation }\end{array}$ & $\begin{array}{l}=15.34 \\
\text { betwee }\end{array}$ & $\begin{array}{l}\text { 4. } d f=26 \mathrm{f} \\
\text { en } C D 44\end{array}$ & $\begin{array}{l}=0.000 \\
\text { expressic }\end{array}$ & $\begin{array}{l}05 . F^{2}=87.09 \\
\text { ion and DFS }\end{array}$ & of ovarian canc & \\
\hline
\end{tabular}

Table 2 Egger's test of funnel plot asymmetry

\begin{tabular}{llrl}
\hline Clinicopathological parameters & t value & df & P value \\
\hline Tumor differentiation & 1.78 & 12 & 0.484 \\
Tumor TNM stage & 1.08 & 16 & 0.714 \\
Primary residual tumor & 0.66 & 3 & 0.997 \\
Response to chemotherapy & 3.42 & 3 & 0.174 \\
Age & 6.15 & 4 & 0.142 \\
Lymphatic metastasis & 2.97 & 5 & 0.243 \\
Histology & 0.66 & 8 & 0.322 \\
Ascites & 0.67 & 4 & 0.327 \\
Overall survival & 2.26 & 11 & 0.531 \\
Disease free survival & 0.21 & 4 & 1.000 \\
\hline
\end{tabular}

df deflection

and metastasis, it has been suggested that the expression of CD44 or certain CD44 variants could serve as valuable candidates for early detection, or as a prognostic predictor for gynecologic malignancies. Although some studies reported that high levels of CD44 expression was associated with a poor prognosis in ovarian cancer patients [17, 28], On the contrary, other groups concluded that CD44 expression had no influence on the survival of patients with ovarian cancer $[15,27]$. This inconsistency may result from small sample size in each individual study. Here, we summarized the pooled data from these studies to increase the statistical power and better evaluate the prognostic values of the expression status of CD44 and its variants in ovarian cancer. To the best of our knowledge, this is the first meta-analysis of published data to evaluate the association between CD44 expression and prognosis in ovarian cancer.

It is important to note that there may be some potential limitations regarding our meta-analysis. First, variation in definitions of clinical outcomes, measurements and experimental procedures might contribute to betweenstudy heterogeneity. It is particularly difficult to address the issue of variations in the definitions of clinical outcomes among different studies. Second, potential publication bias may also be a concern. We restricted our review to articles published in English or Chinese language because other languages were not accessible to the readers, which could favor the positive data that are more often published in English while the negative ones tend to be more often reported in other native languages.

\section{Conclusion}

Our findings demonstrate that CD44 expression is associated with a higher tumor TNM stage among ovarian cancer patients. Moreover, ovarian cancer patients with positive CD44 expression exhibit a worse clinical outcome than those with negative CD44 expression. Further studies with larger sample sizes will be warranted to validate the findings of our meta-analysis in the future. 


\section{Abbreviations}

IHC: immunohistochemistry; OS: overall survival; DFS: disease-free survival; ND: not document.

\section{Authors' contributions}

LJ drafted the manuscript and took responsibility for data acquisition. DD did the statistical analysis and was responsible for manuscript preparation. Both authors read and approved the final manuscript.

\section{Author details}

${ }^{1}$ Department of Assisted Reproduction, Shanghai Ninth People's Hospital, School of Medicine, Shanghai Jiao Tong University, 639 Zhizaoju Road, Shanghai 200011, China. ${ }^{2}$ Department of Gynecology, Obstetrics and Gynecology Hospital, Fudan University, 419 Fangxie Road, Shanghai 200011, China.

\section{Acknowledgements}

This research was supported in part by Grants 81401183 (DD) from the National Science Foundation of China, and Grant 11ZR1404100 (DD) from the Shanghai Science and Technology Commission, Shanghai Key Laboratory of Female Reproductive Endocrine-Related Diseases.

\section{Competing interests}

The authors declare that they have no competing interests.

\section{Funding}

This research was supported in part by Grants 81401183 (DD) from the National Science Foundation of China, and Grant 11ZR1404100 (DD) from the Shanghai Science and Technology Commission, Shanghai Key Laboratory of Female Reproductive Endocrine-Related Diseases.

Received: 13 July 2016 Accepted: 26 December 2016 Published online: 05 January 2017

\section{References}

1. Jemal A, Siegel R, Ward E, Hao Y, Xu J, Murray T, et al. Cancer statistics, 2008. CA Cancer J Clin. 2008;58(2):71-96.

2. Velasco-Velázquez MA, Homsi N, De La Fuente M, Pestell RG. Breast cancer stem cells. Int J Biochem Cell Biol. 2012;44(4):573-7.

3. Zeimet A, Reimer D, Sopper S, Boesch M, Martowicz A, Roessler J, et al. Ovarian Cancer Stem Cells. Neoplasma. 2012;59(6):747.

4. Silva IA, Bai S, McLean K, Yang K, Griffith K, Thomas D, et al. Aldehyde dehydrogenase in combination with CD133 defines angiogenic ovarian cancer stem cells that portend poor patient survival. Cancer Res. 2011:71(11):3991-4001.

5. Wang Y-C, Yo Y-T, Lee H-Y, Liao Y-P, Chao T-K, Su P-H, et al. ALDH1-bright epithelial ovarian cancer cells are associated with CD44 expression, drug resistance, and poor clinical outcome. Am J Pathol. 2012;180(3):1159-69.

6. Patrawala L, Calhoun T, Schneider-Broussard R, Li H, Bhatia B, Tang S, et al. Highly purified CD44 \& plus; prostate cancer cells from xenograft human tumors are enriched in tumorigenic and metastatic progenitor cells. Oncogene. 2006;25(12):1696-708.

7. Takaishi S, Okumura T, Tu S, Wang SS, Shibata W, Vigneshwaran R, et al. Identification of gastric cancer stem cells using the cell surface marker CD44. Stem Cells. 2009;27(5):1006-20.

8. Du L, Wang H, He L, Zhang J, Ni B, Wang $X$, et al. CD44 is of functional importance for colorectal cancer stem cells. Clin Cancer Res. 2008:14(21):6751-60.

9. Bourboulia D, Stetler-Stevenson WG, editors. Matrix metalloproteinases (MMPs) and tissue inhibitors of metalloproteinases (TIMPs): positive and negative regulators in tumor cell adhesion. Seminars in cancer biology. New York: Elsevier; 2010

10. Wang SJ, Wong G, de Heer AM, Xia W, Bourguignon LY. CD44 variant isoforms in head and neck squamous cell carcinoma progression. Laryngoscope. 2009:119(8):1518-30.

11. Yamada Y, Itano N, Narimatsu H, Kudo T, Hirohashi S, Ochiai A, et al. CD44 variant exon 6 expressions in colon cancer assessed by quantitative analysis using real time reverse transcriptase-polymerase chain reaction. Oncol Rep. 2003;10(6):1919-24.
12. Afify AM, Craig S, Paulino AF, Stern R. Expression of hyaluronic acid and its receptors, CD44 s and CD44v6, in normal, hyperplastic, and neoplastic endometrium. Ann Diagn Pathol. 2005;9(6):312-8.

13. Afify AM, Ferguson AW, Davila RM, Werness BA. Expression of CD44S and CD44v5 is more common in stage III than in stage I serous ovarian carcinomas. Appl Immunohistochem Mol Morphol. 2001;9(4):309-14.

14. Dong W-G, Sun X-M, Yu B-P, Luo H-S, Yu J-P. Role of VEGF and CD44v6 in differentiating benign from malignant ascites. World J. 2003:9(11):2596-600

15. Cho EY, Choi Y, Chae SW, Sohn JH, Ahn GH. Immunohistochemical study of the expression of adhesion molecules in ovarian serous neoplasms. Pathol Int. 2006;56(2):62-70.

16. Shi J, Zhou Z, Di W, Li N. Correlation of CD44v6 expression with ovarian cancer progression and recurrence. BMC Cancer. 2013;13(1):182.

17. Tjhay F, Motohara T, Tayama S, Narantuya D, Fujimoto K, Guo J, et al. CD44 variant 6 is correlated with peritoneal dissemination and poor prognosis in patients with advanced epithelial ovarian cancer. Cancer Sci. 2015;106(10):1421-8.

18. Chen H, Hao J, Wang L, Li Y. Coexpression of invasive markers (UPA, CD44) and multiple drug-resistance proteins (MDR1, MRP2) is correlated with epithelial ovarian cancer progression. Br J Cancer. 2009;101(3):432-40.

19. Gao Y, Foster $R$, Yang $X$, Feng $Y$, Shen JK, Mankin HJ, et al. Up-regulation of CD44 in the development of metastasis, recurrence and drug resistance of ovarian cancer. Oncotarget. 2015;6(11):9313-26.

20. Zhou L, Jiang Y, Yan T, Di G, Shen Z, Shao Z, et al. The prognostic role of cancer stem cells in breast cancer: a meta-analysis of published literatures. Breast Cancer Res Treat. 2010;122(3):795-801.

21. Parmar MK, Torri $V$, Stewart L. Extracting summary statistics to perform meta-analyses of the published literature for survival endpoints. Stat Med. 1998;17(24):2815-34

22. Hong SC, Song JY, Lee JK, Lee NW, Kim SH, Yeom BW, et al. Significance of CD44v6 expression in gynecologic malignancies. J Obstet Gynaecol Res. 2006:32(4):379-86.

23. Liu M, Mor G, Cheng H, Xiang X, Hui P, Rutherford T, et al. High frequency of putative ovarian cancer stem cells with CD44/CK19 coexpression is associated with decreased progression-free intervals in patients with recurrent epithelial ovarian cancer. Reprod Sci. 2013;20(5):605-15.

24. Rodriguez-Rodriguez L, Sancho-Torres I, Mesonero C, Gibbon D, Shih W, Zotalis G. The CD44 receptor is a molecular predictor of survival in ovarian cancer. Med Oncol. 2003:20(3):255-63.

25. Ross JS, Sheehan CE, Williams SS, Malfetano JH, Szyfelbein WM, Kallakury BV. Decreased CD44 standard form expression correlates with prognostic variables in ovarian carcinomas. Am J Clin Pathol. 2001;116(1):122-8.

26. Sillanpää S, Anttila MA, Voutilainen K, Tammi RH, Tammi MI, Saarikoski SV, et al. CD44 expression indicates favorable prognosis in epithelial ovarian cancer. Clin Cancer Res. 2003:9(14):5318-24.

27. Steffensen KD, Alvero AB, Yang Y, Waldstrøm M, Hui P, Holmberg JC, et al. Prevalence of epithelial ovarian cancer stem cells correlates with recurrence in early-stage ovarian cancer. J Oncol. 2011;2011:941876.

28. Wang H, Tan M, Zhang S, Li X, Gao J, Zhang D, et al. Expression and significance of CD44, CD47 and c-met in ovarian clear cell Carcinoma. Int J Mol Sci. 2015;16(2):3391-404.

29. Zhang J, Chang B, Liu J. CD44 standard form expression is correlated with high-grade and advanced-stage ovarian carcinoma but not prognosis. Human Pathol. 2013:44(9):1882-9.

30. Zhu L-C, Gao J, Hu Z-H, Schwab CL, Zhuang H-Y, Tan M-Z, et al. Membranous expressions of Lewis y and CAM-DR-related markers are independent factors of chemotherapy resistance and poor prognosis in epithelial ovarian cancer. Am J Cancer Res. 2015:5(2):830.

31. Xu YX. Expression and significance of CD44v6 and PCNA in Ovarian Carcinoma [D]. Dalian: Dalian medical university; 2009.

32. Li HZ, Li WW, Wei SP, Bo YS, Han YJ, Li RY. Study on the expression of CDI33, CD44 and Notchl in ovarian epithelial carcinoma. China Med Herald. 2012;9(19):21-3.

33. Jiang YM, Chen AP. The significance of Ezrin and CD44 expression in Ovarian Cancer. Eval Anal Drug-Use Hosp China. 2010:4:344-6.

34. Zhong JX, Shi GS. Role of CD44v6 in ovarian cancer. J Nantong Univ. 2001;21(2):135-6.

35. Frank NY, Schatton T, Frank MH. The therapeutic promise of the cancer stem cell concept. J Clin Investig. 2010;120(1):41. 
36. Zhang G, Wang Z, Luo W, Jiao H, Wu J, Jiang C. Expression of potential cancer stem cell marker ABCG2 is associated with malignant behaviors of hepatocellular carcinoma. Gastroenterol Res Pract. 2013;2013:782581.

37. Tummala M, McGuire W. Recurrent ovarian cancer. Clin Adv Hematol Oncol. 2005;3(9):723-36

38. Nihei Z, Ichikawa W, Kojima K, Togo S, Miyanaga T, Hirayama R, et al. The positive relationship between the expression of CD44 variant 6 and prognosis in colorectal cancer. Surg Today. 1996;26(9):760-1.

39. Al-Hajj M, Wicha MS, Benito-Hernandez A, Morrison SJ, Clarke MF. Prospective identification of tumorigenic breast cancer cells. Proc Natl Acad Sci. 2003;100(7):3983-8.

40. Hong SP, Wen J, Bang S, Park S, Song SY. CD44-positive cells are responsible for gemcitabine resistance in pancreatic cancer cells. Int J Cancer. 2009;125(10):2323-31.

41. Gallatin WM, Weissman IL, Butcher EC. A cell-surface molecule involved in organ-specific homing of lymphocytes. Nature. 1982;304(5921):30-4.

42. Idzerda RL, Carter WG, Nottenburg C, Wayner EA, Gallatin WM, St John T. Isolation and DNA sequence of a cDNA clone encoding a lymphocyte adhesion receptor for high endothelium. Proc Natl Acad Sci. 1989;86(12):4659-63

43. Liang $Y$, Fang $T, X u H$, Zhuo Z. Expression of CD44v6 and Livin in gastric cancer tissue. Chin Med J. 2012;125(17):3161-5.

44. Zhang $Y$, Wei J, Wang $H$, Xue $X, A n Y$, Tang D, et al. Epithelial mesenchymal transition correlates with CD24 + CD44 + and CD133 + cells in pancreatic cancer. Oncol Rep. 2012;27(5):1599-605.

45. Cho SH, Park YS, Kim HJ, Kim CH, Lim SW, Huh JW, et al. CD44 enhances the epithelial-mesenchymal transition in association with colon cancer invasion. Int J Oncol. 2012;41(1):211-8.

46. Biddle A, Gammon L, Fazil B, Mackenzie IC. CD44 staining of cancer stemlike cells is influenced by down-regulation of CD44 variant isoforms and up-regulation of the standard CD44 isoform in the population of cells that have undergone epithelial-to-mesenchymal transition. PLoS ONE. 2013;8(2):e57314

47. Zöller M. CD44: can a cancer-initiating cell profit from an abundantly expressed molecule? Nat Rev Cancer. 2011;11(4):254-67.

\section{Submit your next manuscript to BioMed Central and we will help you at every step:}

- We accept pre-submission inquiries

- Our selector tool helps you to find the most relevant journal

- We provide round the clock customer support

- Convenient online submission

- Thorough peer review

- Inclusion in PubMed and all major indexing services

- Maximum visibility for your research

Submit your manuscript at www.biomedcentral com/submit 